

\title{
Experimental and modeling study of 1-octene jet stirred reactor oxidation
}

Xiangzan Meng, Olivier Herbinet, Tianyou Wang, Frédérique Battin Leclerc

\section{To cite this version:}

Xiangzan Meng, Olivier Herbinet, Tianyou Wang, Frédérique Battin Leclerc. Experimental and modeling study of 1-octene jet stirred reactor oxidation. Fuel, 2017, 207, pp.763-775. 10.1016/j.fuel.2017.06.128 . hal-01565730

\section{HAL Id: hal-01565730 \\ https://hal.science/hal-01565730}

Submitted on 20 Jul 2017

HAL is a multi-disciplinary open access archive for the deposit and dissemination of scientific research documents, whether they are published or not. The documents may come from teaching and research institutions in France or abroad, or from public or private research centers.
L'archive ouverte pluridisciplinaire HAL, est destinée au dépôt et à la diffusion de documents scientifiques de niveau recherche, publiés ou non, émanant des établissements d'enseignement et de recherche français ou étrangers, des laboratoires publics ou privés. 


\title{
Experimental and modeling study of 1-octene jet-stirred reactor oxidation
}

\author{
Xiangzan Meng1,2, Olivier Herbinet1 ${ }^{1}$, Tianyou Wang², Frédérique Battin-Leclerc1,*
}

${ }^{1}$ Laboratoire Réactions et Génie des Procédés, CNRS, Université de Lorraine, Nancy, France

${ }^{2}$ State Key Laboratory of Engines, Tianjin University, Tianjin 300072, China

Published in Fuel, Volume 207, 1 November 2017, Pages 763-775

\section{Highlights}

- Experimental study of the oxidation of 1-octene in a jet-stirred reactor (500-1100 K).

- Detailed speciation of obtained products.

- A new detailed kinetic model developed for 1-octene oxidation.

- Computed kinetic analyses highlighting the specific pathways for large alkene oxidation.

\begin{abstract}
The oxidation of 1-octene has been studied in a jet-stirred reactor for temperatures from 500 to $1100 \mathrm{~K}$, at atmospheric pressure, with dilute mixtures of equivalence ratios of $0.25,0.5,1.0$, and 2.0 in helium. The initial fuel mole fraction was set as 0.005 . Product formation has been investigated using gas chromatography. In addition to usual $\mathrm{C}_{0}-\mathrm{C}_{4}$ oxidation products, the produced mole fractions of 1,4-pentadiene, cyclohexene, ethylcyclohexene, $C_{5}-C_{8}$ aldehydes, 2-octanone, octenal, hexyl-oxirane, and 2-propyl,5-hydroxytetrahydrofuran have been quantified. Following the same kinetic rules as in a model recently developed for 1-hexene, a new model has been written for 1-octene oxidation. This new model allows an acceptable prediction of most of the newly obtained experimental results, as well as of previous literature ones. The most important deviations were encountered for aldehydes, ketones and cyclic alkenes indicating missing reaction pathways for these compounds.
\end{abstract}

Keywords: 1-octene; low temperature oxidation; detailed chemical kinetic modeling

* frederique.battin-leclerc@univ-lorraine.fr 


\section{Introduction}

Since alkenes are important components of gasoline [1], the oxidation kinetics of linear alkenes including 5 to 6 carbon atoms has been frequently investigated [2-16]. However, there is only very few experimental studies concerning the reactivity of larger linear alkenes. Tanaka et al. [17] have measured the pressure profile during the ignition of the 3 linear heptene isomers in a rapid compression machine at $827 \mathrm{~K}$ and $4.16 \mathrm{MPa}$. The ignition of four linear octene isomers, including 1-octene, was investigated by Hellier et al. [18] on a diesel engine supplied with a range of single-molecule fuels. Piperel et al. [19] investigated the impact of acetaldehyde and NO addition on the 1-octene oxidation under simulated HCCI conditions in a jet-stirred reactor at 10 atm, temperatures from 560 to $1160 \mathrm{~K}$, and equivalence ratio of 0.75 . In the shock tube study at high pressures $(\mathrm{P}=3.8-6.2 \mathrm{MPa})$ and temperatures $(\mathrm{T}=850-1500 \mathrm{~K})$ of the oxidation of methyl trans-2-nonenoate and methyl trans-3-nonenoate by Fridlyand et al. [20], 1-octene (and trans-2octene) was (were) taken as the reference fuel for comparison. The same shock tube has been used to study the oxidation of linear decene isomers under similar experimental conditions [21]. In the case of the studies of 1-octene oxidation by Piperel et al. [19] and Fridlyand et al. [20], only a few products, i.e. water, carbon oxides, formaldehyde, and $\mathrm{C}_{1}-\mathrm{C}_{4}$ hydrocarbons, were quantified. Notably products including 8 atoms of carbon produced by the primary reactions of the reactant were not measured.

The objective of the present paper is then to describe a new experimental and modeling study of 1-octene oxidation. The experiments were performed in jet-stirred reactor with gas chromatography analyses in order to detect the widest range of reaction products, including $\mathrm{C}_{8}$ compounds, for equivalence ratios from 0.25 to 2 . A new detailed kinetic model has been developed. It was built using the same rules as that previously described for 1-hexene [13].

\section{Experimental method}

As in many organic compound oxidation studies [22], experiments were carried out in a heated isothermal jet-stirred reactor (JSR). Gas chromatography was used as the analytical method. The reactive gases, with helium as dilutant, entered the spherical JSR made out of quartz through four nozzles, positioned in the center of the reactor, and designed in order to ensure a perfect gas mixing and to avoid concentration gradients inside the reactor [23]. To also limit thermal gradients inside the reactor, the gaseous mixture was heated to the reactor temperature in a quartz annular pre-heating zone prior to entering the spherical vessel. The residence time in this zone was negligible compared to the residence time in the reactor $(\tau)$ which was taken equal to 
$2 \mathrm{~s}$. The reactor and pre-heating zone were heated using Thermocoax resistance wires. The reaction temperature was measured by a type $\mathrm{K}$ thermocouple positioned at the center of the reactor. The pressure in the reactor $(P)$ was controlled using a needle valve positioned at the downstream of the reactor and taken equal to $106.7 \mathrm{kPa}$.

Helium and oxygen were provided by Messer (purities of 99.99\% and 99.999\%, respectively) with flows to the reactor controlled using flow rate controllers. 1-Octene was provided by Aldrich (purity of 98\%) and used without further purification. The liquid flow was controlled using a liquid-Coriolis-flow-controller, mixed with helium and passed through an evaporator before being mixed with oxygen prior entering to the reactor. The relative uncertainty in gas flow rates was assumed to be around $5 \%$.

The gases leaving the reactors were analyzed using three gas chromatographs (GCs) connected on-line to the exit of the reactor through heated transfer lines kept at $423 \mathrm{~K}$ to avoid condensation:

- $\quad$ The first GC equipped with a thermal conductivity detector and a Carbosphere packed column was used to quantify $\mathrm{O}_{2}, \mathrm{CO}, \mathrm{CO}_{2}$ and $\mathrm{CH}_{4}$.

- The second GC equipped with a flame-ionization detector and a PlotQ capillary column was used to quantify molecules containing up to five carbon atoms. The flame-ionization detector was preceded by a nickel catalyst for the hydrogenation of carbonyl functions. This technique enables a more accurate quantification of species like $\mathrm{CO}, \mathrm{CO}_{2}$ and formaldehyde.

- The third GC was equipped with a flame-ionization detector and a HP-5 capillary column for quantifying molecules containing at least five carbon atoms.

A fourth off-line GC fitted with a Plot Q or a HP-5MS column, and coupled with a mass spectrometer, was used for identification. Response factors were determined by injecting calibration mixtures or using the effective carbon number method [24]. Relative uncertainties in mole fractions were estimated to be $\pm 5 \%$ for species which were calibrated using standards and $\pm 10 \%$ for species which were calibrated using the effective carbon number method. The peak of formaldehyde has a long tail compared to other species, and co-elution occurs with the peaks of three other oxygenates: oxirane, acetaldehyde and methanol. The peak of methanol is usually very small and located in the tail of that of acetaldehyde. In the present work, methanol was identified but not quantified due to a too strong co-elution with acetaldehyde. Nevertheless the 
accurate quantification of oxirane, acetaldehyde and formaldehyde was possible. The strategy used for the quantification consists in integrating all co-eluted peaks, the peak of oxirane, and the peak of acetaldehyde/methanol. The peak area of formaldehyde is obtained by doing a subtraction. This strategy was successfully tested by comparing formaldehyde mole fractions obtained using it and an independent diagnostic: cavity ting-down spectroscopy. An excellent agreement was obtained as it can be seen in the case of the oxidation of $n$-pentane (see Figure 1 in ref [25]).

\section{Detailed kinetic model}

\subsection{Model development}

The 1-octene oxidation model presented hereafter, together with a glossary giving the linear notation corresponding to the name of each species used in the model, can be found in the SM under CHEMKIN format. All the related simulations have been performed using CHEMKIN PRO [26]. As previously done in the case of 1-hexene [13], a basis of this new model has been generated thanks to EXGAS software which was used to automatically generate model for the oxidation of many components of fuels and biofuels [27], with some reaction pathways and kinetic data updated according to the recent literature. EXGAS software was in the past used to generate detailed kinetic models for hexene and heptene isomers [10].

A reaction mechanism generated by EXGAS contains three parts:

- $\quad \mathrm{A} \mathrm{C}_{0}-\mathrm{C}_{2}$ reaction base, including all the reactions involving radicals or molecules containing less than three carbon atoms.

- A comprehensive primary mechanism with all the reactions of the initial organic reactants and oxygen, and of the derived free radicals. For 1-octene oxidation, the primary mechanism includes "ene" and "retro-rene" molecular reactions, 1-octene unimolecular initiations, the bimolecular initiations with $\mathrm{O}_{2}$ or between two 1-octene molecules, the additions of $\mathrm{H}$ atoms and $\dot{\mathrm{O}} \mathrm{H}, \dot{\mathrm{C}} \mathrm{H}_{3}$, and $\mathrm{HO}_{2}$ radicals to the 1-octene double bond, the abstractions of alkylic and allylic $\mathrm{H}$ atoms from the 1-octene molecule, the additions of alkylic, and allylic radicals to oxygen to form peroxy radicals, the alkylic, allylic and peroxy radical isomerisations involving a cyclic transition state including a ring with from 4 to 8 members, radical decompositions by $\beta$-scission or to produce cyclic ethers or branching agents, and allylic radical combinations including especially the combination with $\mathrm{HO}_{2}$ radicals. 
- A lumped secondary mechanism, including reactions consuming the molecular products of the primary mechanism which do not react in the reaction base.

Note that in the primary mechanism, in the case of the peroxy radicals obtained by addition to $\mathrm{O}_{2}$ of alkylic radicals produced by addition of $\mathrm{OH}$ radicals to the double bond, isomerisations include the Waddington mechanism leading to aldehyde formation [28]. Thermochemical data for molecules or radicals are automatically generated based on group and bond additivity methods proposed by Benson [29].

To be consistent with the reactions and rate parameters described in details with the development of our new model in the case of 1-hexene [13], the following reactions have been up-dated or added:

- The rate coefficients for the thermal dissociation and the reverse recombination of $\mathrm{H}_{2} \mathrm{O}_{2}$ have been updated to the values proposed by Troe [30].

- The rate constant for the bimolecular initiation of $\mathrm{C}_{3}-\mathrm{C}_{4}$ alkenes with $\mathrm{O}_{2}$ has been taken as those proposed by Baulch et al. [31] in the case of propene.

- The rate constants of the reactions of OHH radicals with the fuel, including additions with hydroxyl adduct stabilization, additions followed by decomposition, and $\mathrm{H}$-abstractions, have been estimated from the calculations of Zádor et al. [32] on propene using the same pressure dependence. For 1-hexene modeling, these reaction changes, which were especially important for allylic $\mathrm{H}$-abstractions and additions followed by decomposition, were shown to have a significant effect on fuel consumption and aldehyde production [13].

- The rate constants for the reactions via the Waddington mechanism, i.e. the reactions of hydroxyperoxyradicals through a cyclic transition state to produce $\dot{O} H$ radicals and aldehydes, have been taken from the calculations of Lizardo-Huerta et al. [33]. During 1-hexene modeling, this up-date resulted mainly in significant changes in the prediction of aldehyde distribution [13].

- The reactions between of $\mathrm{C}_{3}-\mathrm{C}_{8}$ allylic and $\mathrm{HO}_{2}$ radicals have been added using the kinetics proposed for allyl radical by Goldsmith et al. [34,35] (with A-factors of all these pathways divided by two in this 1-octene model). During 1-hexene modeling, the addition of these new 
reaction pathways notably influenced the fuel reactivity, and was also acted as the main route to unsaturated aldehydes [13].

- The rate constant for the $\mathrm{H}$-abstraction from 1-octene by $\mathrm{CH}_{3} \mathrm{O}$ radicals giving an allylic radical has been taken from the recent work of Zhang et al. [36] (40 T2.9 $\left.\exp (-8609 \mathrm{cal} / \mathrm{RT}) \mathrm{s}^{-1}\right)$ instead of the older values $\left(1.8 \times 10^{12} \exp (-1200 \mathrm{cal} / \mathrm{RT}) \mathrm{s}^{-1}\right)$ proposed by Bounaceur et al. [10]. During 1-hexene modeling [13], this up-date massively decreased the predicted production of methanol, with only a slight decrease of simulated fuel consumption. In the present work, the use of the older value [10] leads to a slightly better agreement for fuel consumption in lean mixtures, but to a $20 \%$ overprediction in stoichiometric conditions, with no notable change for product formation.

- The rate constant of the reaction with $\alpha$-hydroxyalkyl radicals to yield aldehydes/ketones and $\mathrm{HO}_{2}$ radicals has been taken from the work of da Silva et al. [37]. This new theoretically calculated rate constant for this reaction, which is the main route via aldehydes/ketones of the same size as the reactant, is larger by at least three orders of magnitude than the estimated value of Bounaceur et al. [10]. However, a division by a factor of 10 of this value did not have a significant effect on the octanal / 2-octanone prediction, especially below $800 \mathrm{~K}$.

- The formation and the decomposition of $\mathrm{C}_{8}$ keto- and aldo-hydroperoxides have been detailed and have replaced the reactions automatically generated using the EXGAS lumping method [38]. During 1-hexene modeling [13], this up-date massively increased the predicted production of propanal, with no effect on simulated fuel consumption.

- The rate constants of the decomposition of large hydroperoxides has been taken as: at $1 \mathrm{~atm}$, the rate expression of $4.0 \times 10^{15} \exp (-42,900 \mathrm{cal} / \mathrm{RT}) \mathrm{s}^{-1}$, as proposed by the review Baulch et al. [31] for $\mathrm{C}_{2} \mathrm{H}_{5} \mathrm{OOH}$ decomposition, and, at $10 \mathrm{~atm}$, the rate expression of $1.5 \times 10^{16} \exp (-42,000$ cal/RT) s $\mathrm{s}^{-1}$ as adopted by Curran et al. [39] in their iso-octane mechanism.

- The rate constants for the decomposition by $\mathrm{C}-\mathrm{C}$ bond breaking of $\mathrm{C}_{8}$ alkenyl and allylic radicals were adopted from the recent theoretical work of Bian et al. [40].

- The 1,6-endo-cycloaddition and 1,7-endo-cycloaddtion of oct-1-en-6-yl and oct-1-en-7-yl radicals, followed by the decomposition by $\mathrm{CH}$ bond breaking of the obtained cyclic radicals, have been added with rate constants taken from Wang et al. [41] (with the A-factor divided by two in the case of the 1,6-endo-cycloadditions). 
The two last updates were not considered in the 1-hexene model [13], but were found to be important for a larger reactant such as 1-octene.

\subsection{Simulations of previous literature data}

The model was first used to simulate literature data: the results of Piperel et al. [19] obtained also using a jet-stirred reactor, but at higher pressures than that in the present study, as well as the results of Fridlyand et al. [20] measured in a shock tube.

Figure 1 displays a comparison between simulations using the current model and experimental results of Piperel et al. [19]. A reasonable agreement is observed over all the temperature range for fuel, water, carbon oxides and formaldehyde, with nevertheless, an underprediction of the reactivity between 650 and $750 \mathrm{~K}$.


Figure 1. Comparison between simulated (with the current model) and experimental data for the JSR experiments by Piperel et al. [19] (pressure of $10 \mathrm{~atm}$, equivalence ratio of 0.75).

Figure 2 shows the same comparison for the results of Fridlyand et al. [20] who provided the detailed experiment conditions and results. The initial pressures, temperatures and reaction times were set as the same as in the experiments. From the experimental data, it seems the initial fuel mole fraction is $110 \mathrm{ppm}$, rather than $100 \mathrm{ppm}$. In their simulation, Fridlyand et al. 
[20] also used $110 \mathrm{ppm}$ as the initial fuel mole fraction. The initial fuel mole fraction of oxygen is set as stated (1200 ppm). The shock tube experiment was simulated using a constant pressure batch reactor model as did by Fridlyand et al. [20].
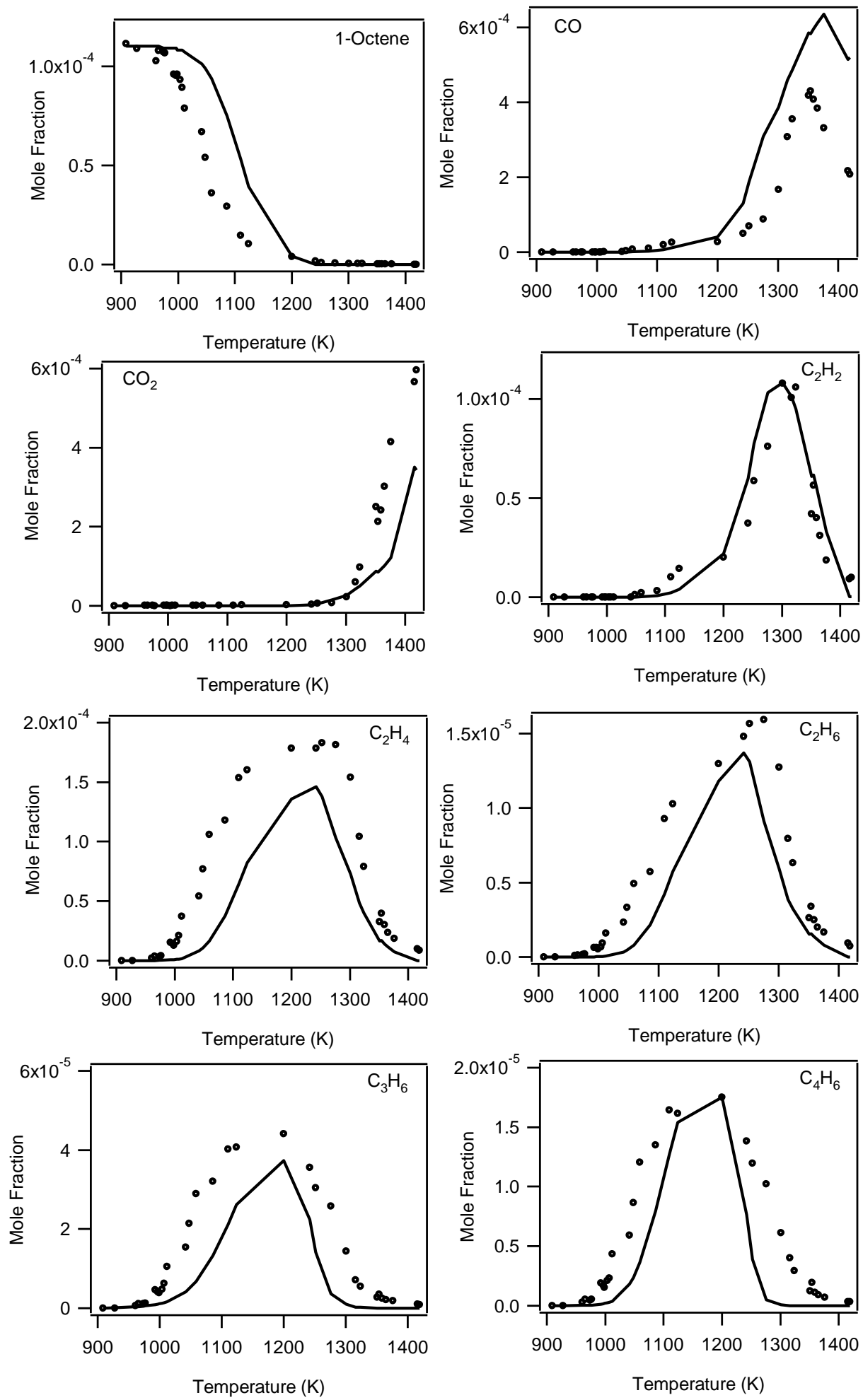

Figure 2. Comparison between simulated (with the current model) and experimental data for the shock tube experiments by Fridlyand et al. [20] (pressure of $5 \mathrm{MPa}$, equivalence ratio of 1.1). 
The reactant mole fraction profile indicated that the reactivity with the current model would not be high enough: it is similar to simulation results with the model of methyl 9-decenoate by Herbinet et al. [42] which included a high temperature 1-octene model. Fridlyand et al. [20] obtained a better agreement but with an adjustment of the rate constant for the fission of the allylic C-C bond by a factor of 2-5. However, it can be also seen in Figure 2 that the current 1-octene model predicts well the evolution with temperature of the product mole fraction, with a good simulation of the temperature at which the maximum mole fraction is observed.

\section{Discussion about JSR experimental results and comparison with simulations using the new model}

Figures 3-7 show experimental results obtained in JSR for temperatures from 500 to $1100 \mathrm{~K}$, at atmospheric pressure, with dilute mixtures at equivalence ratios of $0.25,0.5,1.0$, and 2.0 in helium, as well as comparison with simulations performed using the previously described model. The mole fractions obtained for all performed measurements can be found in a spreadsheet of the SM.

Figure 3. Mole fraction profiles of reactants and $\mathrm{C}_{0}-\mathrm{C}_{1}$ reaction products (except formaldehyde) for 1-octene oxidation in a jet-stirred reactor at $\varphi=0.25,0.5,1.0$ and $2.0, P=106.7 \mathrm{kPa}, \tau=2 \mathrm{~s}$.

Full symbols are experiments and lines simulations.
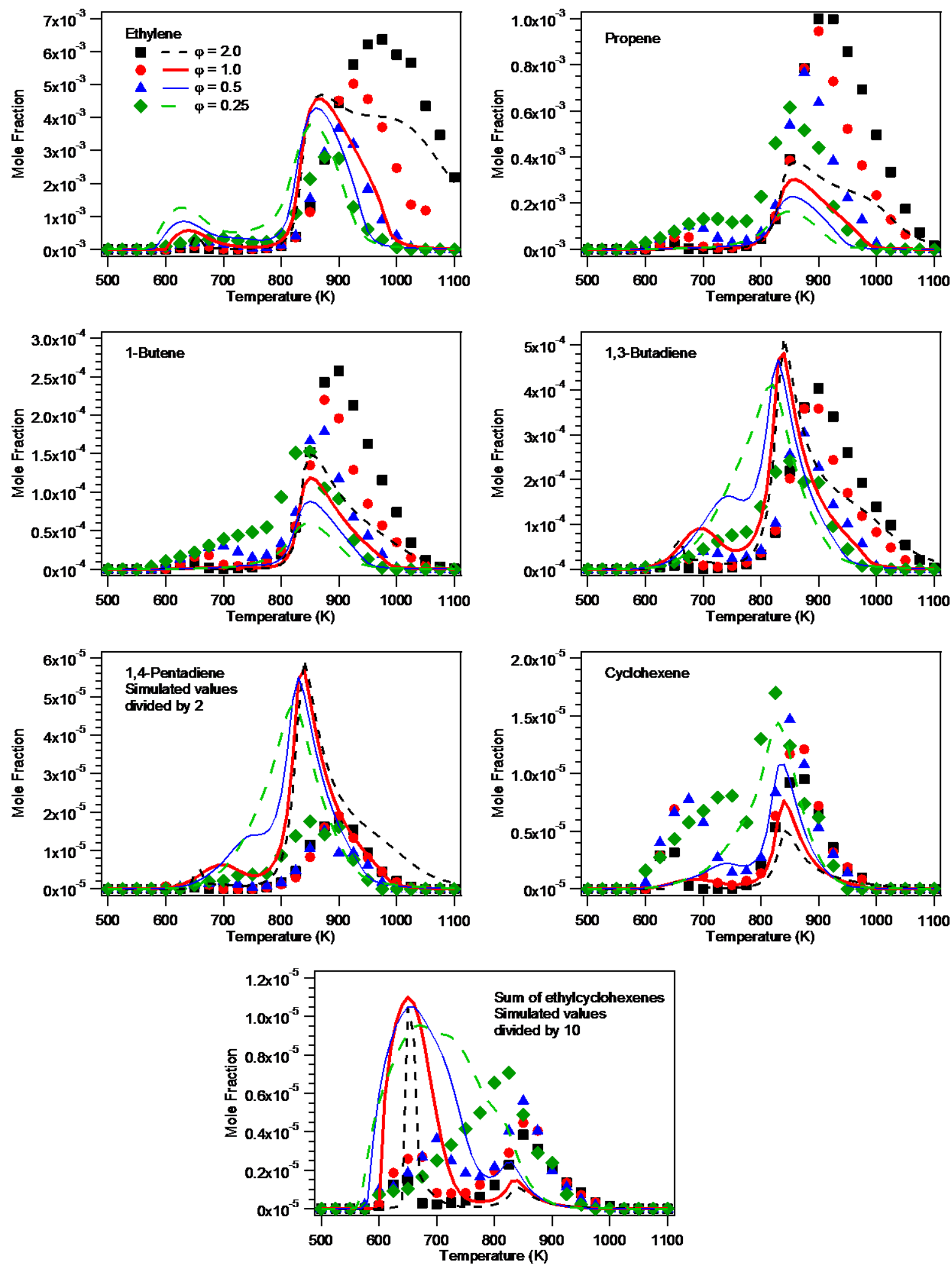

Figure 4. Mole fraction profiles of alkenes and dienes produced during 1-octene oxidation in a 
jet-stirred reactor at $\varphi=0.25,0.5,1.0$ and $2.0, P=106.7 \mathrm{kPa}, \tau=2 \mathrm{~s}$. Full symbols are experiments and lines simulations.
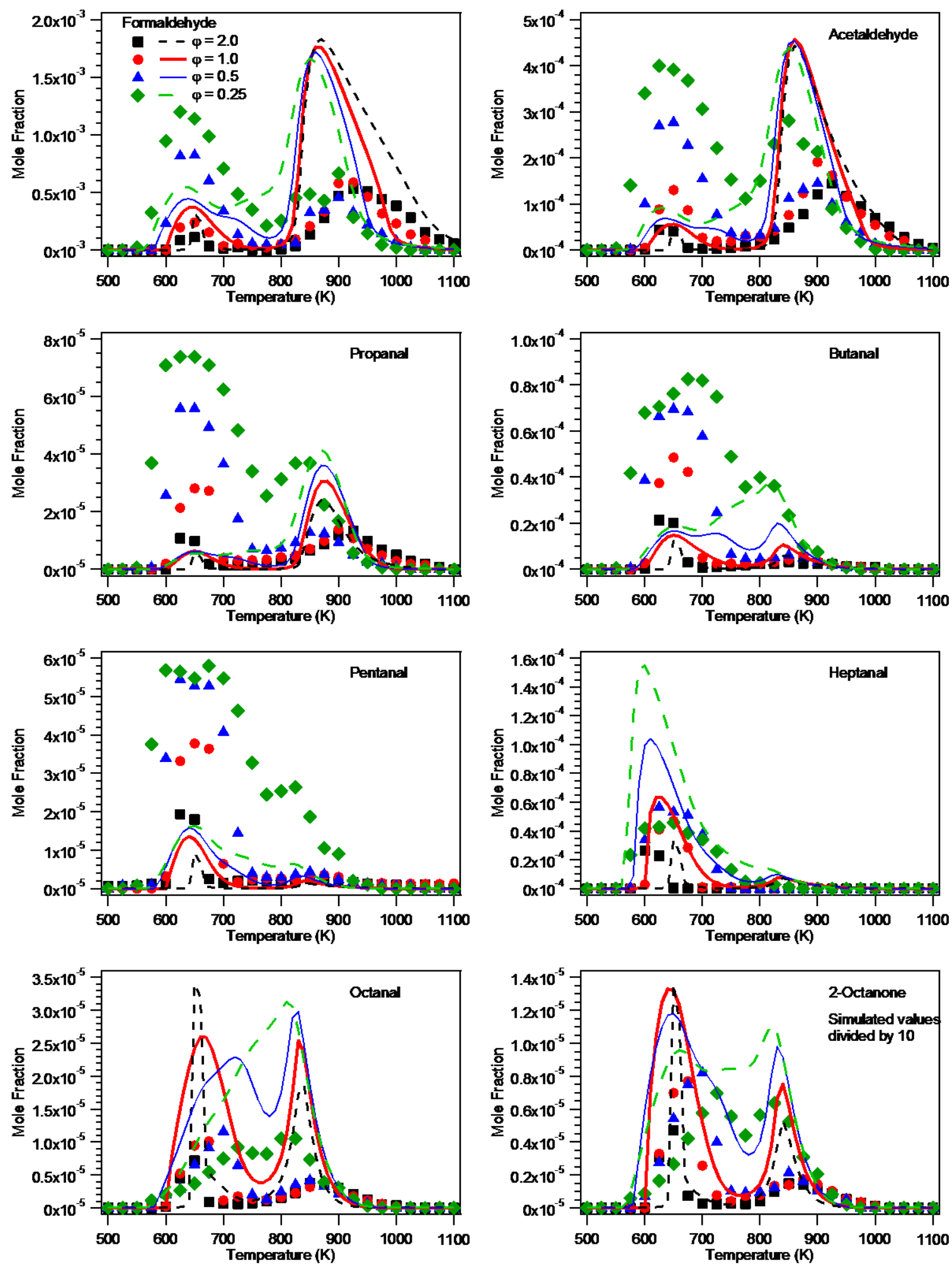

Figure 5. Mole fraction profiles of saturated aldehydes and ketone with a carbonyl function formed during 1-octene oxidation in a jet-stirred reactor at $\varphi=0.25,0.5,1.0$ and 2.0, $P=106.7$ $\mathrm{kPa}, \tau=2 \mathrm{~s}$. Full symbols are experiments and lines simulations. 



Figure 6. Mole fraction profiles of unsaturated aldehydes with a carbonyl function formed during 1-octene oxidation in a jet-stirred reactor at $\varphi=0.25,0.5,1.0$ and $2.0, P=106.7 \mathrm{kPa}, \tau=2 \mathrm{~s}$. Full symbols are experiments and lines simulations.
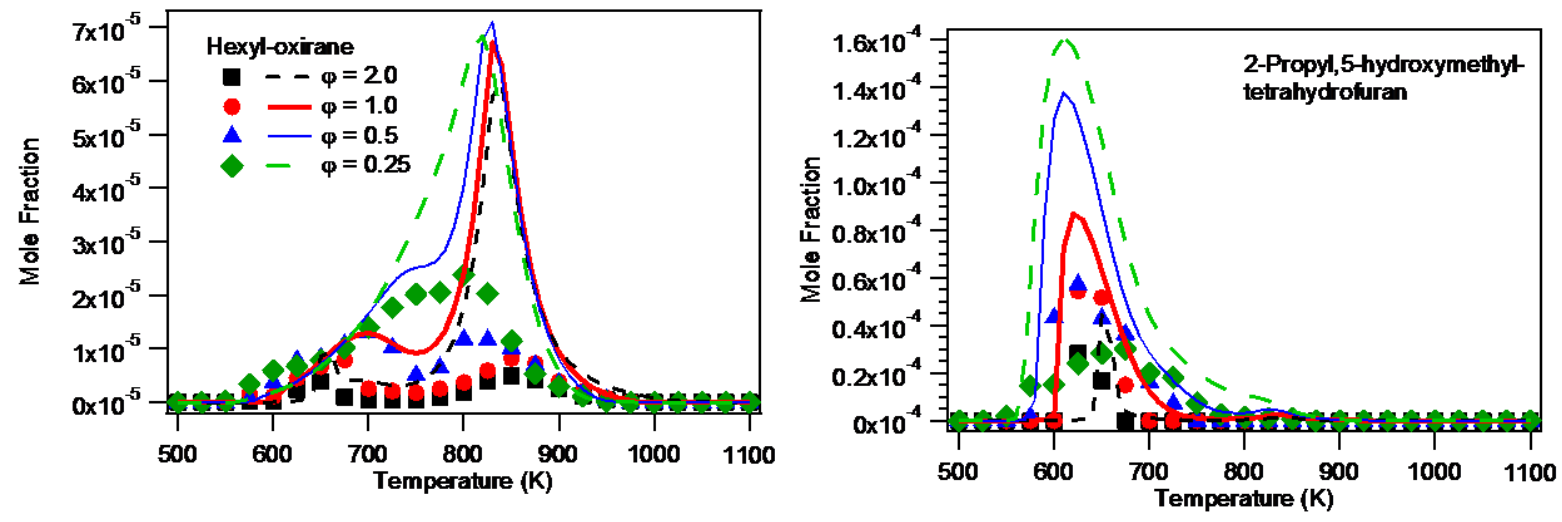

Figure 7. Mole fraction profiles of cyclic ethers formed during 1-octene oxidation in a jet-stirred reactor at $\varphi=0.25,0.5,1.0$ and $2.0, P=106.7 \mathrm{kPa}, \tau=2 \mathrm{~s}$. Full symbols are experiments and lines simulations. 


\subsection{Reactants, carbon oxides and methane}

Figure 3 displays the evolution with temperature of fuel conversion and of the mole fraction of oxygen, carbon oxides, and methane. A negative temperature coefficient (NTC) zone is observed at all equivalence ratios. The temperature range where this NTC zone is observed expands as mixture becomes leaner. When the equivalence ratio decreases, the fuel reactivity is significantly promoted at low temperatures below $800 \mathrm{~K}$. This promoting effect is gradually reduced at higher temperatures. The model reproduced reasonably well the experimental results including the influence of changing temperatures and equivalence ratios. However, the effect of equivalence ratio on the low temperature fuel reactivity is underpredicted. Note that, in a narrow temperature range around $650 \mathrm{~K}$, a sharp peak of the fuel reactivity is predicted for the equivalence ratio of 2.0. This peak was not experimentally observed. This temperature corresponds also to sharp peaks in the mole fraction profiles of several products: ethylcyclohexenes, octanal and 2-octanone, as described further in the text.

\subsection{Alkenes and dienes}

$\mathrm{C}_{2}-\mathrm{C}_{4}$ alkenes, $\mathrm{C}_{4}-\mathrm{C}_{5}$ dienes and cyclic alkenes, namely cyclohexene and ethylcyclohexenes, were detected and quantified during these experiments. Their mole fraction profiles are displayed in Figure 4. Note that, 1,3-octadiene was also detected, but it was not quantified due to a strong co-elution with another unknown product. The decrease of equivalence ratio promotes the formation of alkenes and dienes below $800 \mathrm{~K}$ while it reduces the production of these unsaturated hydrocarbons when temperature continues increasing. Reducing equivalence ratio enhances the formation of cycloalkenes at all temperatures. Concerning simulated results, despite significant discrepancies in absolute values for 1,4-pentadiene and ethylcyclohexenes, the evolution of product mole fractions with temperature and equivalence ratio is correctly predicted by the model. 1,4-pentadiene is mainly produced from the $\beta$-scission of the oct-1-en-4yl radical, and it is overpredicted by almost a factor of four. Further consumption reactions of 1,4-pentadiene need to be investigated to improve this prediction.

It is interesting that cyclohexenes bearing an ethyl function were detected during the oxidation of 1-octene. As is shown in Figure 8, the oct-1-en-6-yl radical formed by H-abstractions from 1 -octene proceed via an 1,6-endo-cycloadditon to produce the 3-ethylcyclohexyl radical. This radical can subsequently eliminate an $\mathrm{H}$ atom either by reaction with $\mathrm{O}_{2}$ or by $\beta$-scission to form 
3-ethylcyclohexene or 4-ethylcyclohexene. Such formation pathways were investigated in recent theoretical studies $[40,41]$. However, the current mechanism lacks of low-temperature reactions related to ethyl-cyclohexane and ethyl-cyclohexenes, for which very few papers can be found in the literature. Although recent experimental, theoretical and modeling studies of ethylcyclohexane oxidation were recently published [43-45] and detailed kinetic models are available for the high-temperature oxidation and pyrolysis of this molecule [45], there is still no validated model for its low-temperature oxidation. As a result, the production of ethylcyclohexenes is largely overpredicted at temperatures below $800 \mathrm{~K}$; by contrast, the predictions at high temperatures are close to the experimental data. This incomplete knowledge about the kinetics of the consumption of ethyl-cyclohexenes is certainly one of the major reason explaining that the present 1-octene model consistently underestimates the reactivity in the lowtemperature region, not only in comparison with the present experiments but also with literature ones.



Figure 8. Scheme of formation of ethylcyclohexenes.

\subsection{Products with a carbonyl function}

Several products with a carbonyl function, such as saturated and unsaturated aldehydes were detected and quantified during the experiments. Figure 5 shows the experimental results for saturated aldehydes and 2-octanone. The decrease of equivalence ratio promotes the production of aldehydes. This is correctly predicted by the model. However, the high temperature productions of formaldehyde, acetaldehyde and propanal is overpredicted, while the low temperature productions of C1 to C5 aldehydes is mostly underpredicted. The large aldehyde underprediction observed at low-temperature especially for lean mixtures is partly related to the reactivity underprediction obtained under these conditions, but also certainly to missing formation pathways which are important for large alkenes while they did not play such a big role during 1-hexene oxidation, since the predictions concerning aldehydes were better with the model of Meng et al. [13].

Heptanal, the main product of the Waddington mechanism apart from formaldehyde, is shown to be mainly formed in the low-temperature range. The model reasonably predicts its evolution 
with temperature and equivalence ratio. Although hexanal is another expected product of the Waddington mechanism (see a scheme of possible pathways through Waddington mechanism in Figure 9), its formation pathway is notably less favored than that of heptanal, and a co-elution with the fuel also makes it hard to be measured quantitatively in our GC experiments.



Figure 9. Scheme of the possible reactions pathways through the Waddington mechanism.

Figure 5 also indicates a production of octanal and 2-octanone, which are mainly produced by the oxidation of $\alpha$-hydroxyalkyl radicals as shown in Figure 10. Our previous 1-hexene modeling study [13] showed that this type of reaction had an inhibiting effect on the fuel reactivity. The model predicts reasonably well the formation of octanal, while the mole fractions of 2-octanone are overpredicted by a factor around 10 . Nevertheless, the shape of the mole fraction evolution with temperature and the influence of equivalence ratio are well predicted. The overprediction of 2-octanone may be attributed to the lack of consuming reactions in the current model. Note that, there is a large peak production of octanal and 2-octanone around $650 \mathrm{~K}$ in rich mixtures. Note that, with the help of the work of Pelucchi et al. [46] on aldehydes, the reactions consuming octanal were considered in greater details than for octanone. As only few information was available on the kinetics of reactions consuming ketones [47], the lumped ketone consumption submechanism generated by EXGAS was kept. 


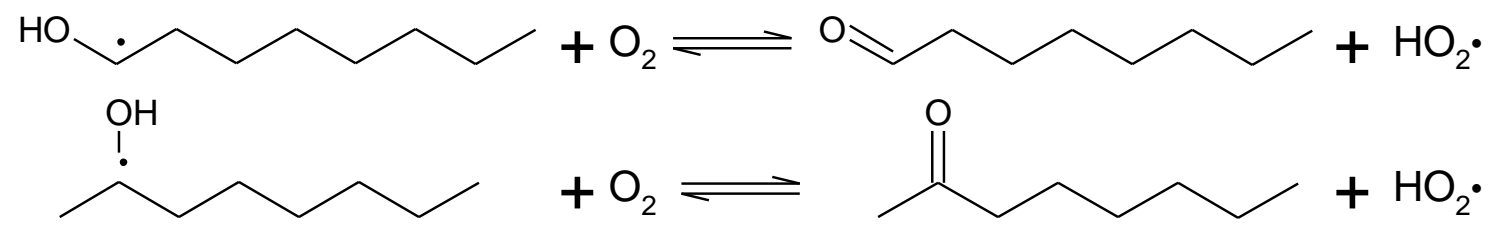

Figure 10. Oxidations of $\alpha$-hydroxyalkyl radicals to form octanal and 2-octanone.

As suggested in recent studies of alkenes oxidation [12,48-50], reactions of allylic and $\mathrm{HO}_{2}$ radicals are important reactivity promoting reactions, and are also the main pathways of producing unsaturated aldehydes. Acrolein, 2-butenal and 2-octenal were detected and quantified during these experiments and their mole fraction evolutions with temperature are depicted in Figure 6. Acrolein and 2-butenal are both produced at low and high temperatures. The high temperature production of these small unsaturated aldehydes can be attributed to the large formation of propene and 1-butene yielded from the $\beta$-scission of fuel radicals. While the simulations for acrolein compare well with experimental data, 2-butenal mole fractions are notably underpredicted. Contrary to the experimental result, the predicted formation of 2butenal occurs only above $800 \mathrm{~K}$. Since the $\beta$-scissions of fuel radicals are more favored at high temperatures, the production of 2-octenal, which is mainly due to the reaction of the oct-1-en-3-yl with $\mathrm{HO}_{2}$ radicals, is significantly lower at high-temperatures than at low temperatures. The fact that 2-octenal is mainly produced at low temperatures is correctly predicted by the model, but the magnitude of the mole fraction is significantly overpredicted. Such results may be due to a lack of consuming reactions of 2-octenal, which requires further investigation as relevant studies are scarce in literature.

\subsection{Cyclic ethers}

Cyclic ethers were already found to be produced during the oxidation of alkenes [12]. The reaction of alkenes with $\mathrm{HO}_{2}$ radical forming the oxirane (formed via direct epoxidation) is a major reaction pathway both at low and high temperatures. As is shown in Figure 7, when decreasing equivalence ratio, the production of hexyl-oxirane, which is produced by reaction of 1-octene and $\mathrm{HO}_{2}$ radical, is promoted regardless of the temperature.

Some other cyclic ethers were also detected during the oxidation of 1-octene. Their structures and corresponding retention time are displayed in a chromatogram shown in Figure 11. Only 2-propyl,5-hydroxymethyl-tetrahydrofuran was quantified. The quantification of the other cyclic ethers was difficult due to co-elution and relatively low amount of production. 


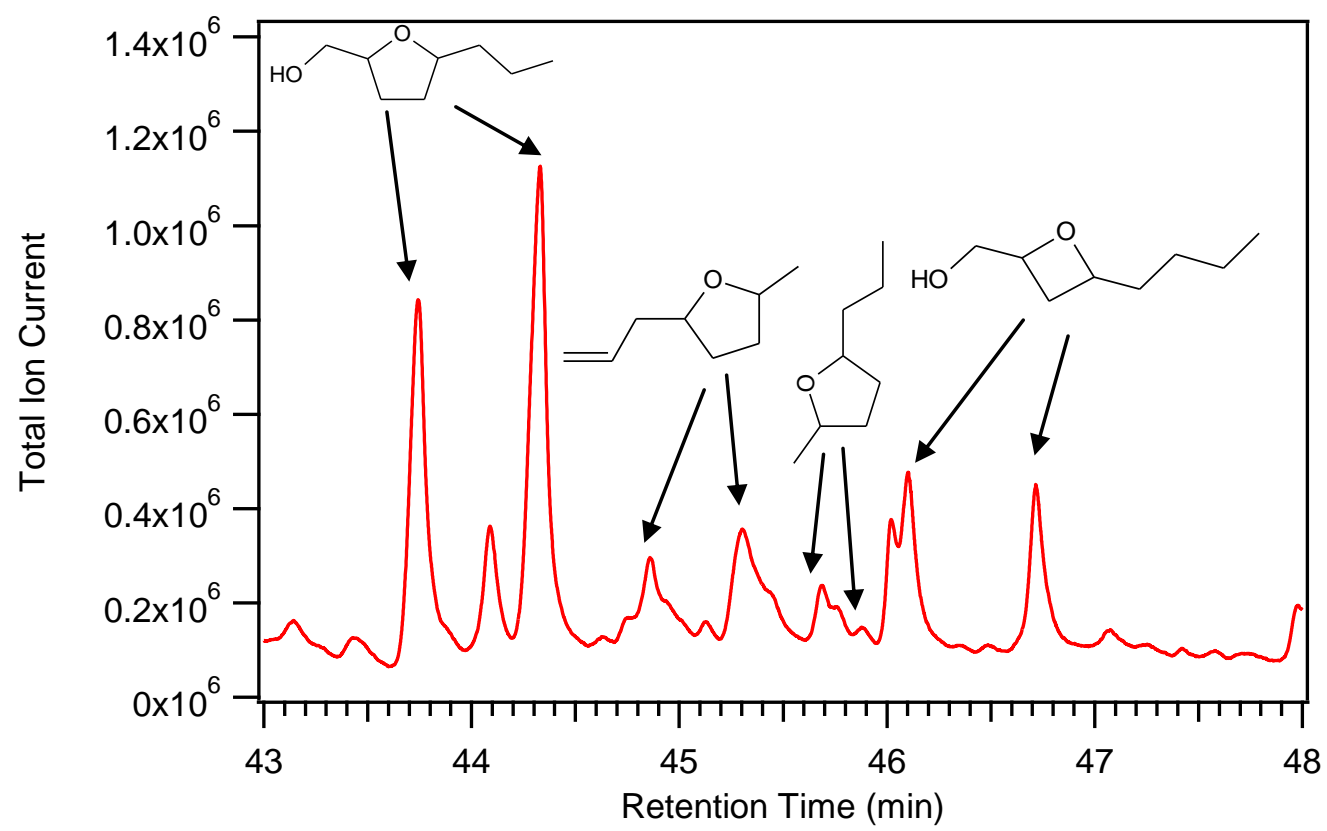

Figure 11. A chromatogram showing some cyclic ethers detected during the experiments plotted versus retention time.

The formation of hydroxycyclic ethers is a concurrent reaction channel to the Waddington mechanism, which was proposed in alkene models since 2005 [6]. Hydroxycyclic ethers were experimentally detected and quantified by Battin-Leclerc et al. in their 2014 study on hexenes [12]. In this study, 2-propyl,5-hydroxymethyl-tetrahydrofuran was detected and quantified during the oxidation of 1-octene, as is shown in Figure 7.

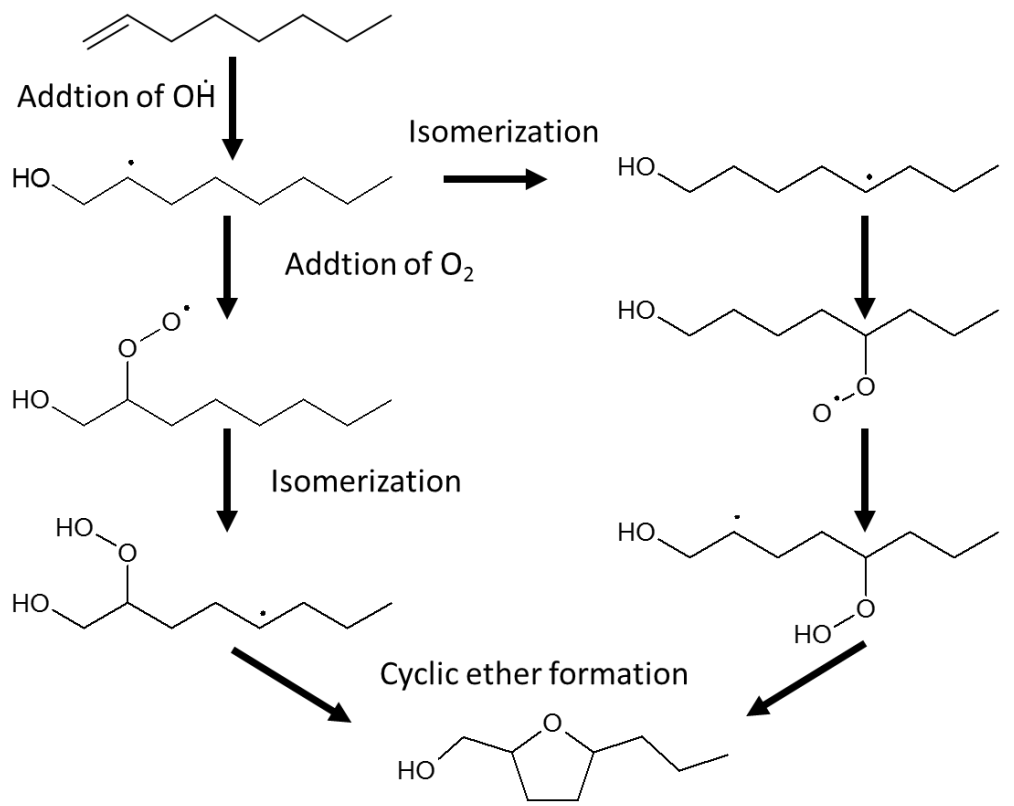

Figure 12. Possible formation pathways of 2-propyl,5-hydroxymethyl-tetrahydrofuran for 1-octene. 
The formation pathways of this species is described in Figure 12: hydroxyl radical adds first to the terminal carbon of the double bond. This is followed by an addition to oxygen, an isomerization and 2-propyl,5-hydroxymethyl-tetrahydrofuran is finally obtained. The adduct formed by the addition of hydroxyl radical to 1-octene can also isomerize to another radical bearing a hydroxyl function, and finally leads to the formation of 2-propyl,5-hydroxymethyltetrahydrofuran via similar reactions. Since the addition of $\dot{\mathrm{O} H}$ radicals is favored at low temperatures, 2-propyl,5-hydroxymethyl-tetrahydrofuran is mainly produced below $800 \mathrm{~K}$. The evolution with temperature and equivalence ratio of 2-propyl,5-hydroxymethyl-tetrahydrofuran mole fraction is correctly predicted. The overprediction of the mole fraction values may be largely due to the lumping treatment of cyclic isomers in the model.

\subsection{Sensitivity and flow rate analyses}

Figure 13 presents sensitivity analysis for the oxidation of 1-octene at $650 \mathrm{~K}$, the low temperature around which the highest reactivity is typically observed under all equivalence ratios investigated in this study. In addition, an overview of the 1-octene oxidation reaction flux at $650 \mathrm{~K}$ under stoichiometric condition is given in Figure 14.



Figure 13. Sensitivity analysis for fuel conversion at $650 \mathrm{~K}$ under the conditions of Figure 3. 
(a) Initialized by $\mathrm{OH}$ and $\mathrm{H}$ additions



(b) Initialized by $\mathrm{H}$ abstractions



Figure 14. Flow rate analysis at $650 \mathrm{~K}$ under the conditions of Figure 3 for stoichiometric mixtures, $\mathrm{KHP}=$ ketohydroperoxide, $\mathrm{KHP}-\mathrm{OH}$ = hydroxyketohydroperoxide, species in boxes were detected during the JSR experiments. Broken arrows correspond to several elementary steps; numbers with arrows corresponds to the flux of intermediate consumption. 
As is shown in Figure 14a, similar to the low temperature oxidation of 1-hexene [13], the additions of $\mathrm{OH}$ radical and $\mathrm{H}$-atom to the double bond are important low temperature consumption pathways of 1-octene oxidation. The addition of $\mathrm{OH}$ radical is the initial reaction that leads to the Waddington mechanism, the formation of hydroxyl cyclic ethers, and hydroxyketohydroperoxides, the decomposition of which is an important low temperature branching step. It is observed that the two adducts of OH radical to 1-octene could lead to the production of octanal and 2-octanone, but with different branching ratios. Only $14.7 \%$ of the adducts obtained by the terminal addition of $\dot{\mathrm{O}} \mathrm{H}$ can isomerize in two steps to produce hydroxyalkyl radicals which can be oxidized to form octanal. In contrast, $87.5 \%$ of the adducts produced from the central addition of $\mathrm{OH}$ can isomerize in two steps via $\mathrm{R} 83 \mathrm{C} 8 \mathrm{H} 160 \mathrm{H}$ to the give hydroxyalkyl radicals which can react to form 2-octanone. The isomerization of R83C8H16OH is shown to have a strong inhibiting effect on the low temperature reactivity, while the competing oxygen addition reaction promotes the reactivity as illustrated in Figure 13.

The addition of $\mathrm{H}$-atom to the terminal end of the double bond is shown to have a lager flow rate than that to the central end in Figure 14a. The adducts are octyl radicals, which would typically go through the low temperature oxidation pathways as in the oxidations of long chain alkanes, where the formation of ketohydroperoxides contributes to the low temperature branching step. Moreover, the terminal addition of $\mathrm{H}$-atom is shown to promote the reactivity in Figure 13.

As illustrated in Figure 14b, $\mathrm{H}$ atom abstractions are other important fuel consuming pathways during 1-octene oxidation. As 1-octene has two more carbon atoms than 1-hexene, it produces two more akenyl radicals along with more isomerizations, which makes the low temperature oxidation of 1-octene more complex. As is shown in Figure 13, most H-atom abstraction reactions promote the reactivity except for the reaction that produces the oct-1-en-6-yl radical (R32C8H15Z). This is because the oct-1-en-6-yl radical can proceed via an 1,6-endocycloadditon to produce the 3-ethylcyclohexyl radical, which mostly reacts to form 3ethylcyclohexene or 4-ethylcyclohexene. Note that reactions leading to the formation of ethylcyclohexenes are shown to have a strong inhibiting effect on the reactivity. By contrast, the addition of $\mathrm{O}_{2}$ to the oct-1-en-6-yl radical is a sensitive promoting reaction as shown in Figure 13.

As is shown in Figure 14b, the allylic oct-1-en-3-yl radical (R27C8H15X) can be produced not only from the abstraction of $\mathrm{H}$-atoms from 1-octene, but also from the isomerizations of other octenyl radicals. The reactions of the oct-1-en-3-yl radical play an important role in the low temperature oxidation of 1-octene. Its combination reactions with $\mathrm{HO}_{2}$ radical are the main 
reactions leading to the formation of unsaturated aldehydes, such as 2-octenal and acrolein. Moreover, a product of the reaction of oct-1-en-3-yl with $\mathrm{HO}_{2}$ radical, namely the pentyl radical, could lead to low temperature branching reactions, which is also highlighted by the sensitivity analysis as shown in Figure 13. A certain amount (20.4\%) of the oct-1-en-3-yl radical could also go directly through $\beta$-scission to produce 1,3-butadiene and a butyl radical. This butyl radical can promote the low temperature reactivity by forming the branching agent via addition to $\mathrm{O}_{2}$, as both shown in Figures 13 and 14b.

\section{Conclusion}

This paper presents a speciation study of the oxidation of 1-octene in a jet-stirred reactor for temperatures from 500 to $1100 \mathrm{~K}$, at atmospheric pressure, with dilute mixtures of equivalence ratios of $0.25,0.5,1.0$, and 2.0 in helium. A detailed oxidation mechanism of 1-octene is also developed to reproduce the experimental data obtained herein as well as previous studies in the literature. A broad range of oxidation products, such as 1,4-pentadiene, cyclohexene, ethylcyclohexene, $\quad \mathrm{C}_{5}-\mathrm{C}_{8}$ aldehydes, 2-octanone, octenal, hexyl-oxirane, and 2-propyl,5-hydroxytetrahydrofuran have been quantified, most of which are satisfactorily described by the model.

However, even if based on the same kinetic rules as that proposed for 1-hexene [13], the agreement obtained with the 1-octene model is all together less satisfactory than for the $\mathrm{C}_{6}$ reactant. This is due to an increase in the complexity of the chemistry with increasing the size of the studied 1-alkene. The 1,6-endo-cycloaddition of the oct-1-en-6-yl radical, which finally leads to the formation of ethylcyclohexenes is shown to be important to the low temperature oxidation of 1-octene. However, the low temperature reactions producing aldehydes and the pathways consuming ethylcyclohexenes still require further investigations as well as those decomposing long chain carbonyl species, such as octanal, 2-octanone, and 2-octenal.

\section{Acknowledgement}

Xiangzan Meng would like to acknowledge the financial support from the program of China Scholarship Council (NO. 201506250038).

\section{Supplementary material}

Experimental data for the oxidation of 1-octene. 
Mechanism

Thermodynamic properties

Species glossary.

\section{References}

[1] Guibet JC. Fuels and engines. Paris: Publications de l'Institut Français du Pétrole, Editions Technip; 1999.

[2] Prabhu SK, Bhat RK, Miller DL, Cernansky NP. 1-Pentene oxidation and its interaction with nitric oxide in the low and negative temperature coefficient regions. Combust Flame 1996;104:377-90.

[3] Ribaucour M, Minetti R, Sochet LR. Autoignition of $n$-pentane and 1-pentene: Experimental data and kinetic modeling. Symp (Int) Combust 1998;1:345-51.

[4] Minetti R, Roubaud A, Therssen E, Ribaucour M, Sochet LR. The chemistry of pre-ignition of n-pentane and 1-pentene, Combust Flame 1999;118:213-20.

[5] Vanhove G, Ribaucour M, Minetti R. On the influence of the position of the double bond on the low-temperature chemistry of hexenes. Proc Combust Inst 2005;30:1065-72.

[6] Touchard S, Fournet R, Glaude PA, Warth V, Battin-Leclerc F, Vanhove G, et al. Modeling of the oxidation of large alkenes at low temperature. Proc Combust Inst 2005;30:1073-81.

[7] Yahyaoui M, Djebaili-Chaumeix N, Dagaut P, Paillard C-E, Gail S. Kinetics of 1-hexene oxidation in a JSR and a shock tube: Experimental and modeling study. Combust Flame 2006;147:67-78.

[8] Mehl M, Faravelli T, Giavazzi F, Ranzi E, Scorletti P, Tardani A, et al. Detailed chemistry promotes understanding of octane numbers and gasoline sensitivity. Energy Fuels 2006;20:2391-8.

[9] Mehl M, Vanhove G, Pitz WJ, Ranzi E. Oxidation and combustion of the n-hexene isomers: A wide range kinetic modeling study. Combust Flame 2008;155:756-72.

[10] Bounaceur R, Warth V, Sirjean B, Glaude P, Fournet R, Battin-Leclerc F. Influence of the position of the double bond on the autoignition of linear alkenes at low temperature. Proc Combust Inst 2009;32:387-94.

[11] Mehl M, Pitz WJ, Westbrook CK, Yasunaga K, Conroy C, Curran HJ. Autoignition behavior of unsaturated hydrocarbons in the low and high temperature regions. Proc Combust Inst 2011;33:201-8.

[12] Battin-Leclerc F, Rodriguez A, Husson B, Herbinet O, Glaude P-A, Wang Z, et al. Products from the oxidation of linear isomers of hexene. J Phys Chem A 2014;118:673-83. 
[13] Meng X, Rodriguez A, Herbinet O, Wang T, Battin-Leclerc F. Revisiting 1-hexene lowtemperature oxidation. Combust. Flame 2017;181:283-99.

[14] Yang F, Deng F, Zhang P, Hu E, Cheng Y, Huang Z. Comparative study on ignition characteristics of 1-hexene and 2-hexene behind reflected shock waves. Energy Fuels 2016;30:5130-7.

[15] Fan X, Wang G, Li Y, Wang Z, Yuan W, Zhao L. Experimental and kinetic modeling study of 1-hexene combustion at various pressures. Combust Flame 2016;173:151-60.

[16] Yang F, Deng F, Zhang P, Tian Z, Tang C, Huang Z, Experimental and kinetic modeling study on trans-3-hexene ignition behind reflected shock waves, Energy Fuels 2016;30:706-16.

[17] Tanaka S, Ayala F, Keck JC, Heywood JB. Two-stage ignition in HCCI combustion and HCCI control by fuels and additives. Combust Flame 2003;132:219-39.

[18] Hellier P, Ladommatos N, Allan R, Filip S, Rogerson J. The importance of double bond position and cis-trans isomerisation in diesel combustion and emissions. Fuel 2013;105:477-89. [19] Piperel A, Dagaut P, Montagne X. Impact of acetaldehyde and NO addition on the 1-octene oxidation under simulated HCCI conditions. Proc Combust Inst 2009;32:2861-8.

[20] Fridlyand A, Goldsborough SS, Brezinsky K. Chemical kinetic influences of alkyl chain structure on the high pressure and temperature oxidation of a representative unsaturated biodiesel: Methyl nonenoate. J Phys Chem A 2015;119:7559-77.

[21] Fridlyand A, Goldsborough SS, Brezinsky K, Merchant SS, Green WH. Influence of the double bond position on the oxidation of decene isomers at high pressures and temperatures. Proc Combust Inst 2015;35:333-40.

[22] Herbinet 0, Battin-Leclerc F. Progress in Understanding low-temperature organic compound oxidation using a jet-stirred reactor. Int J Chem Kinet 2014;46:619-39.

[23] Herbinet G, Dayma O. Jet-stirred reactor. In: Battin-Leclerc F, Simmie JM, Blurock E, editors. Cleaner combustion, Springer London; 2013, p. 183-210.

[24] Tranchant J. Chromatographie en phase gazeuse. Ed. Techniques Ingénieur; 1996.

[25] Rodriguez A, Herbinet O, Wang Z, Qi F, Fittschen C, Westmoreland PR, et al. Measuring hydroperoxide chain-branching agents during n-pentane low-temperature oxidation. Proc. Combust. Insti. 2017;36:333-42.

[26] Reaction Design. CHEMKIN-PRO 15151. San Diego: 2016.

[27] Blurock E, Battin-Leclerc F, Faravelli T, Green W. Automatic generation of detailed mechanisms. In: Battin-Leclerc F, Simmie JM, Blurock E, editors. Cleaner combustion, Springer London; 2013, p. 59-92.

[28] Stark MS, Waddington DJ. Oxidation of propene in the gas phase. Int J Chem Kinet $1995 ; 27: 123-51$.

[29] Benson SW. Thermochemical kinetics. 2nd ed. New York: John Wiley; 1976. 
[30] Troe J. The thermal dissociation/recombination reaction of hydrogen peroxide III: Analysis and representation of the temperature and pressure dependence over wide ranges. Combust Flame 2011;158:594-601.

[31] Baulch DL, Cobos CJ, Cox RA, Frank P, Hayman G, Just T, et al. Evaluated kinetic data for combustion modeling. Supplement I. J Phys Chem Ref Data 1994; 23:847-1033.

[32] Zádor J, Jasper AW, Miller JA. The reaction between propene and hydroxyl, Phys Chem Chem Phys 2009;11:11040-53.

[33] Lizardo-Huerta JC, Sirjean B, Bounaceur R, Fournet R. Intramolecular effects on the kinetics of unimolecular reactions of $\beta$-HOROO and HOQ ${ }^{\circ} \mathrm{OOH}$ radicals. Phys Chem Chem Phys 2016;18:12231-51.

[34] Goldsmith CF, Klippenstein SJ, Green WH. Theoretical rate coefficients for allyl + HO2 and allyloxy decomposition. Proc Combust Inst 2011;33:273-82.

[35] Goldsmith CF, Green WH, Klippenstein SJ. Role of O2 + QOOH in low-temperature ignition of propane. 1. Temperature and pressure dependent rate coefficients. J Phys Chem A 2012;116:3325-46.

[36] Zhang K, Banyon C, Bugler J, Curran HJ, Rodriguez A, Herbinet O, et al. An up-dated experimental and kinetic modeling study of n-heptane oxidation. Combust Flame 2016;172:11635.

[37] da Silva G, Bozzelli JW, Liang L, Farrell JT. Ethanol Oxidation: Kinetics of the $\alpha$ hydroxyethyl radical + 02 reaction. J Phys Chem A 2009;113:8923-33.

[38] Biet J, Hakka MH, Warth V, Glaude P-A, Battin-Leclerc F. Experimental and modeling study of the low-temperature oxidation of large alkanes. Energy Fuels 2008;22:2258-69.

[39] Curran HJ, Gaffuri P, Pitz WJ, Westbrook CK, A comprehensive modeling study of isooctane oxidation, Combust Flame 2002;129:253-80.

[40] Bian H, Wang Z, Zhang F, Wang Z, Zhu J. Unimolecular reaction properties for the longchain alkenyl radicals. Int J Chem Kinet 2015;47:685-94.

[41] Wang K, Villano SM, Dean AM. Reactivity-structure-based rate estimation rules for alkyl radical h atom shift and alkenyl radical cycloaddition reactions. J Phys Chem A 2015;119:720521.

[42] Herbinet O, Pitz WJ, Westbrook CK. Detailed chemical kinetic mechanism for the oxidation of biodiesel fuels blend surrogate. Combust Flame 2010;157:893-908.

[43] Husson B, Herbinet O, Glaude PA, Ahmed SS, Battin-Leclerc F. Detailed product analysis during low- and intermediate-temperature oxidation of ethylcyclohexane. J Phys Chem A 2012;116:5100-11.

[44] Ning H, Gong C, Tan N, Li Z, Li X. Low- and intermediate-temperature oxidation of ethylcyclohexane: A theoretical study. Combust Flame 2015;162:4167-82. 
[45] Wang Z, Zhao L, Wang Y, Bian H, Zhang L, Zhang F, et al. Kinetics of ethylcyclohexane pyrolysis and oxidation: An experimental and detailed kinetic modeling study. Combust Flame 2015;162:2873-92.

[46] Pelucchi M, Somers KP, Yasunaga K, Burke U, Frassoldati A, Ranzi E, et al. An experimental and kinetic modeling study of the pyrolysis and oxidation of n-C3-C5 aldehydes in shock tubes. Combust. Flame 2015;162:265-86.

[47] Kopp WA, Burke U, Döntgen M, Kröger LC, Minwegen H, Heufer KA, et al. Ab initio kinetics predictions for $\mathrm{H}$-atom abstraction from 2-butanone by $\mathrm{H}$ and $\mathrm{CH} 3$ and the subsequent unimolecular reactions. Proc. Combust. Inst. 2017;36:203-210.

[48] Burke SM, Metcalfe W, Herbinet O, Battin-Leclerc F, Haas FM, Santner J, et al. An experimental and modeling study of propene oxidation. Part 1: Speciation measurements in jetstirred and flow reactors. Combust Flame 2014;161:2765-84.

[49] Li Y, Zhou C-W, Somers KP, Zhang K, Curran HJ. The oxidation of 2-butene: A high pressure ignition delay, kinetic modeling study and reactivity comparison with isobutene and 1butene. Proc Combust Inst 2017;36:403-411.

[50] Zhou C-W, Li Y, O'Connor E, Somers KP, Thion S, Keesee C, et al. A comprehensive experimental and modeling study of isobutene oxidation. Combust Flame 2016;167:353-79. 